\title{
Sustaining cultural industries: Menemen pottery as a cultural heritage
}

\author{
D. Deniz, O. Mengi \& A. C. Ozcan \\ Department of Industrial Design, Izmir University of Economics, Turkey
}

\begin{abstract}
Urban development today, under the influence of cultural economy, occurs around the production, distribution and consumption of culture. In this respect, sustainability of cultural industries that provide social and economic benefits for future developments is located at the core of the design, culture and planning triangle. Pottery production in Menemen, located at the north axis of Izmir, Turkey, despite its strengths regarding its local and very distinctive production practices, currently falls behind the trends due to the lack of promotion and marketing indicators and is in need of new branding strategies. This particular study consists of various data collection procedures in the area. Data analysis has been processed through illustrations and graphics to present the findings. The findings have also been supported by an international workshop held in Menemen in collaboration with Izmir University of Economics, Academy of Fine Arts in Warsaw and Adam Mickiewicz Institute and also the Menemen Pottery Makers Association. The workshop acted as a pilot study for this research, to convey the understanding of the pottery making, to promote the cultural production and to sustain and transfer its unique knowledge transculturally. Finally, this paper proposes a strategic model in order to contribute to sustainability of cultural heritage and development of Menemen.

Keywords: new economy, cultural industries, sustainability, cultural heritage, sustainable development.
\end{abstract}

\section{Introduction}

In the first decade of the twenty-first century, urban restructuring processes were marked by a rising interest in creativity and culture and enthusiasm for branding in cities. The purpose of this paper is to investigate which aspects of the possible 
strategies need to be considered to tackle the current problems and to promote cultural industries and to achieve sustainable cultural development. Menemen has been selected as a case area where the pottery making has long been regarded as heritage since it has been inherited for five generations.

Through the field research conducted at the district, there have been many chances to observe crucial studies on the features of sustainability of cultural industries and also interviews with several masters of pottery making. Initial data has been obtained from the semi-structured interviews with the local pottery makers and NGOs (Non-Government Organizations) in Menemen. The following data has been collected via observations of all 22 of the pottery ateliers, clay-sources and other spatial settings such as pottery exhibits and markets. The paper has also been supported by the workshop practice organized internationally to increase awareness about this unique cultural production. The research findings and the results of the workshop present that sustaining cultural industries is a complex issue and must be considered in a wider perspective and over varied scales and different levels to deliver on its promise.

Consequently, depending on the findings, a strategic model has been introduced for most of the localities of industries based on the cultural production. This strategic model integrates the feasibility, effectiveness and sustainability levels of cultural industry with particular actors and institutions for Menemen and similar geographies.

\section{Urban restructuring and cultural industries}

For the last half-century, urban areas have witnessed major shifts in the mode of production and related economic reformations that have triggered the urban restructuring processes. During the 1950s and 1960s, urban restructuring was based on the mass production and industrial development with a substantial growth of size and height of city centres. Through the 1960s, the character of urban areas and their political context have dramatically altered with the tendency for the decline of industry [1]. In the 1970s, the crises of the Fordist mode of capital accumulation triggered a shift towards the flexible mode of production, internationalization of finance and new global division of labour (Marcuse and Van Kempen [2]); particularly in Western countries as well as the US have seen a considerable transformation into the postFordist mode of production, deindustrialization, geography of capital flows, rise in financial and producer services industries and so on [3]. For the 1980s, Soja [4] claims that there is a "restless formation and reformation of geographical landscapes in 1980s" as a significant transformation of urban areas with rise of service sector under the globalization [4]. Globalization that results in competition has been a process that has brought the decline of manufacturing and rise of service sector specifically in cities. One of the most noticeable consequences of continuous change in previous urban restructurings was the disappearance of the manufacturing and craft sectors. However, later, under the uncertainty of globalization that caused an identity crisis among cities, many urban 
environments have considerably started to call on their cultural heritage to reconstruct the meaning and identity of a unique place.

Since the 1980s, cultural industries has been increasingly noticeable for cultural policy-makers, and started to be added to national and local policies. Cultural industries are defined as goods or services and their contents protected by copyright. Cultural industries are defined as activities that primarily engage in symbolic of which primary economic value comes from their cultural significance and uniqueness. This definition includes both the conventional cultural industries - broadcast media, film, publishing, recorded music, design, architecture, new media - and the traditional arts - visual art, crafts, theatre, music theatre, concerts and performance, literature, museums and galleries [5]. The major effort at international level has been to pull the cultural industries into policy circles. For the national level, cultural heritages have been conserved, sustained as well as promoted through those cultural industry policies. Promoting the small independent sectors within the cultural industries has encouraged the local manufacturers, rather than the ones engaging at the global corporate level [6-8].

\section{Sustainability of cultural industries}

Scott [9] claims that cultural production in the industries demands the existing cultural heritage left over from the previous manufacturing sites to render new places for physical development and economic growth. With the cultural ingredient incorporated to the production and their creative capacities in design, branding, promotion and marketing, cultural industries also carry the potential of providing to the traditional manufacturing industries with an ability to compete internationally. However, sustainability of the structure of cultural industries has always been the concern for various professionals and academic fields.

Alterations in consumption trends after the 1980s have led to the appeal of the unique and special, and have created a tendency towards niche cultural markets and increased the market share of cultural products. Such consumption trends have brought the issue of sustainable growth to the table. Sustainable development studies make not only environmental, but also economical and social sense to the cultural industries as well. Since there are only short-term solutions and precautions so far, particularly in developing countries, the use of heritage in terms of the economic viability of the inhabitants and the further costs involved in correcting badly designed applications and ill-planned policies are certainly much greater than getting it right in the first place.

At that point, also several actors as possible collaborators need to be aware of the risks of a location and understand the potentials of the cultural production before deciding on possible strategic solutions. Therefore, these concepts need to be considered at the beginning of strategic models including environmental, economic and social planning and design decisions in order to provide fully embedded solutions by various actors.

For the environmental, economic and social vitality in cultural industries, especially such case as in Menemen, place branding appears as a useful tool. 
According to Landry and Bianchini, place branding is a driving factor to merge and integrate different parts of the city into a consistent artifact [10]. This claim is very applicable to the case of pottery making in Menemen. For instance, in Barcelona, the discourse that was manifested in the place branding process can be seen in the improvements and developments in the distinctive and unique elements of the city. Construction projects, including enhancement of the cultural and technical infrastructure and unification of major design elements, distributed across the entire city are the major examples of such reimaging process. Many localities all over the world retake and flourish the abandoned or obsolescent districts, especially in Europe and North America such as in London, Glasgow, Hamburg, Berlin, Barcelona, Milan, New York, Montreal, Toronto, San Francisco, and Vancouver. In these cases, new spatiality of cultural industry formations can be regarded as a revival of manufacturing sites, or as a new phase of the urban services economy [11]. Such new phases indicate older manufacturing techniques, inherited knowledge of arts and crafts but served as an appealing dimension of new urban development. Besides, the branding contains the vision of place that extends beyond its borders, creating mental internationally recognized landmarks out of the cultural productions.

In addition, place identity helps to ensure physical, social, and psychological well-being of people and also their social reproduction and consumption needs. It secures the social and physical attachment to a certain place. To Castells' flows of people, money, goods and information is also considered within a vast range of cultural products and experiences. This is crucial especially today where capital, goods, people, and culture flow globally and jeopardize the individuality and authenticity of places through varied taste, belief and cultural identity. In this respect, Kunzmann [12] suggests that there should be mediation between local distinctiveness and global orientation for identity. In addition, there are also some claims that there are some places with cultural identities that have evolved for a period of time. Such cultural districts emerge naturally (and generally with a certain type of class accumulation) like China Town (in NY), Little Italy (in LA), Arabic Quarters and also some villages and cosmopolitan structure [13, 14].

Therefore sustainability of cultural industries needs certain planning and design approaches focusing on the place branding and place identity. Such approach can also indicate particular actors and stakeholders interacting within the economic, social and environmental assets of cultural industries.

\section{Case Study: Menemen pottery as a cultural heritage}

Menemen is a district of Izmir located on the west coast of Turkey. With the population of 138,143 , Menemen covers approximately $694.49 \mathrm{~km}^{2}$ [15]. Its economy depends mainly on agriculture and stockbreeding in large part, yet the production and export of potteries including ceramic and other earthenware products have always been famous across Turkey for centuries. According to interviews with the members of the Menemen Pottery Makers Association, Menemen has been exporting $90 \%$ of its products until 2008 and now serve to 
the domestic market due to the shrinkage of international markets. Pottery makers, who produce $80 \%$ of Turkey's pottery needs and produce items such as flower pots, amphorae and bowls, send their products to adjacent touristic regions. The pottery sector in Menemen currently suffers from the lack of promotion and marketing strategies. The Menemen Pottery Makers Association, which was founded recently with the intention of improving and advertising their pottery, continues to work towards immediate strategies for development and sustainability of the cultural heritage and production in Menemen.
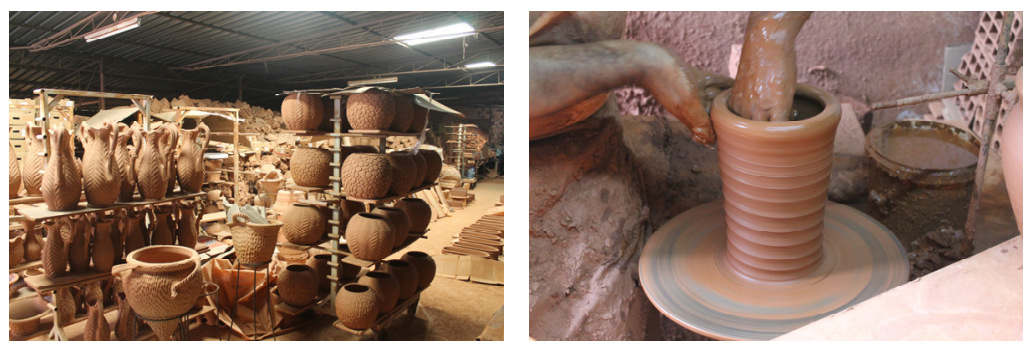

Figure 1: Pottery making in Menemen, Turkey.

\subsection{Kulp workshop as an attempt for promoting the culture}

To meet the sectorial needs and expectations and regain the reputation of the district back through place branding, identity formation and quality of place, Menemen Pottery Association requested long-term cooperation from the Izmir University Economics, Department of Industrial Design. This cooperation has been embodied as a scientific research project aimed at the production of various design-based models for development of Menemen. One of these models has concentrated on bringing out the pottery making potential as a cultural industry, reforming and sustaining this cultural heritage of the district.

Within the research project, the Menemen Kulp Workshop has been initiated with the collaboration of Izmir University of Economics, Turkey, Academy of Fine Arts in Warsaw, Poland and Adam Mickiewicz Institute, Poland where similar cultural assets exist. The academy has been invited to study for ways of branding the Menemen pottery and place, and to propose new designs that will show the quality and identity of the district. The Kulp Workshop has been organized with the participation of Turkish and Polish undergraduate design students for ten days. The project also has had a side purpose of contributing to inter-cultural relations. It has coincided with the 600th anniversary of cultural and diplomatic relations between Turkey and Poland.

The first day of the workshop, an orientation presentation was realized for the students. The following days, several site visits have been organized to observe the physical environment and production techniques in Menemen. After such intense days of examination and analysis, the last days of the workshop has indicated the brainstorming sessions, presentations of the observed problems and possible solutions by the design students. SWOT analysis with the contribution of students has also been shared with some NGOs invited for examining the 
workshop outcomes. Consequently, the students have performed their abilities of design and planning under realistic scenarios for place branding of Menemen as a district. This workshop has been an actual implementation practice of the initiatives for branding and identity reformation of the district. It has helped to give an opportunity to future designers and planners a glimpse of all the stages of the cultural handcrafting in Menemen including the design, production, promotion, and sales processes. It has also helped to create solutions to existing problems. With the help of this internationally organized workshop, all the local and national newspapers and internet portals have focused on the district and cultural production of pottery, as well as this, many interviews have been conducted with the representatives of NGOs, and with academics from Izmir University of Economics, Academy of Fine Arts in Warsaw. The Head of the Menemen Pottery Association says of the project: "We will take a stand in the global arena by creating product designs which are unique to our trademark Menemen pottery."

This workshop has only been one of the initial attempts for sustaining the cultural potential and can be evaluated as one of the tools for place branding to overcome the declining reputation of the district. It has been an understanding of the pottery making as a cultural production and, an implementation attempt to sustain and transfer its unique knowledge transculturally. The research is still in progress and further design-based implications are achievable.

\subsection{Site survey and data collection}

There are 22 organized ateliers, 3 main clay resources, 1 large roadside market and 1 newly founded administration located in Menemen (Figure 2). The data has been collected through semi-structured interviews with all of the ateliers, NGOs (Non-Government Organizations) and through observations of the ateliers, clay-sources and other settings such as pottery exhibits and markets in Menemen.

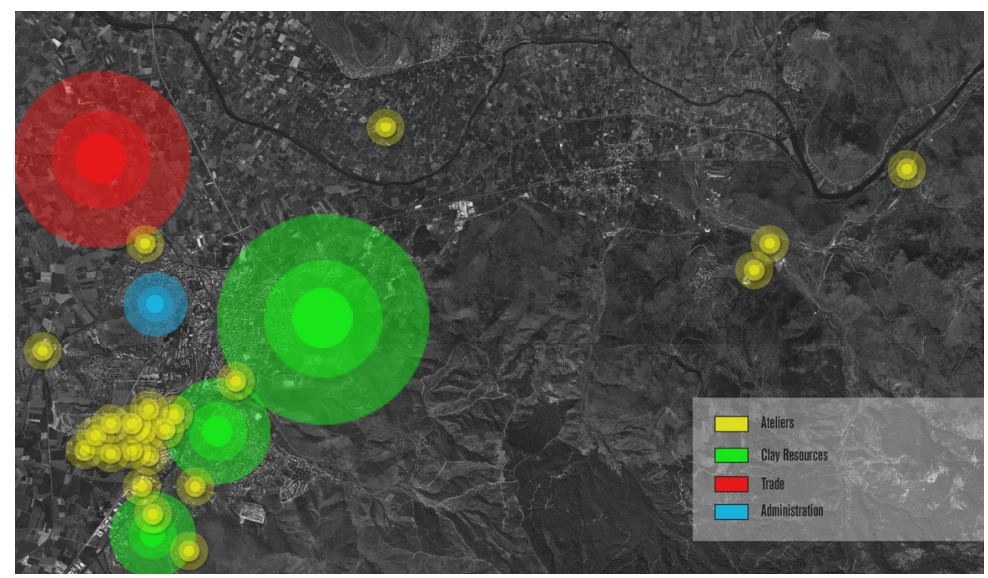

Figure 2: Distribution of pottery making in the case area. 
All the pottery makers in different ateliers have been interviewed for 30 minutes with regard to their professional and know-how history in terms of the cultural heritage and their needs and expectations regarding the pottery making, that together, will be included in the strategic data.

\subsection{Data processing and findings}

According to the results of the first data set derived from the interviews carried out with the current 22 ateliers, the average age of learning pottery making is 10 and the year that the makers started to develop their abilities was from the age of 7 to 12 . The respondents have also claimed that the reason for learning this craft is to gain it as profession, rather than hobby. For the professional evolution and transferring the unique know-how of pottery making, the findings reveal that the profession is learnt mostly from the masters belonging to their families or relatives in comparison to the ones who gained their knowledge from any qualified pottery maker located in Menemen (Figure 3).
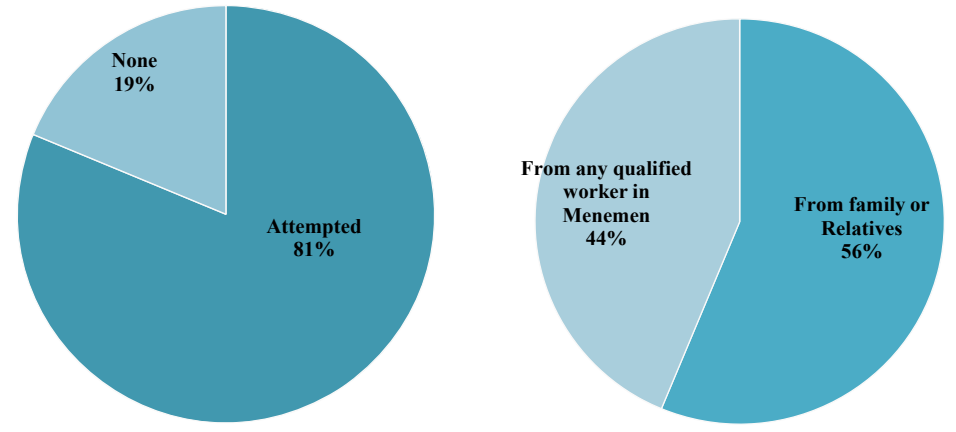

Figure 3: Training new pottery makers (left) and know-how and knowledge resource (right).

Also, the pottery makers have been questioned whether they have shared and exchanged their knowledge and experiences through training others on this craftsmanship. $81 \%$ of them have replied positively. The average number of apprentices trained by them is between 5 and 8 , the total number of the trained pottery makers until today is 78 . However, half of these trained craftsmen have left Menemen due to the place-based and industry-based obstacles. Additionally, all the pottery makers have been found being in this cultural industry to afford their livings. Lastly, for the last three decades the growth of the Menemen pottery as a cultural industry has been considerable in terms of numbers (Table $1)$.

The interviews with the NGOs supported by the questionnaire with the pottery makers show that while the number of ateliers incline, the governmental incentives and provisions stay the same. Therefore, the individual income and rate of the pottery makers decline consequently. 
Table 1: Number of ateliers by years.

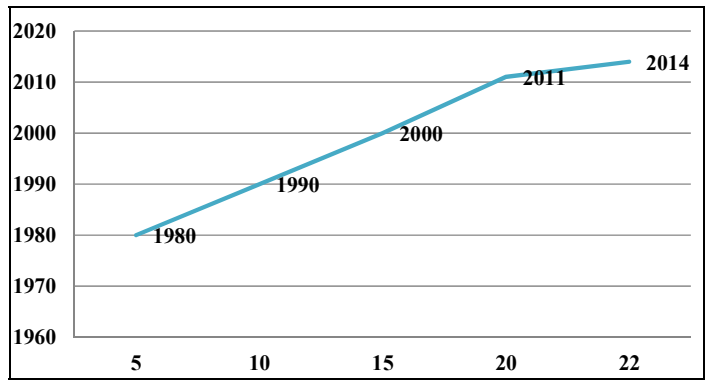

For the second data set questioning their needs and expectations, the major obstacles reported by the pottery makers in Menemen is the cost of manufacturing expenses among others; lack of qualified workers, inefficient role of government, conflictive competition among the pottery makers, environmental problems, declining export rates, lack of promotion for the industry and, research and development for the industry. Two-thirds of the problems about the cost of manufacturing expenses are the cost of clay resource collection $(75 \%)$ as the other quarter is energy source expenditures due to the lack of incentives supplied by the local government (Figure 4).

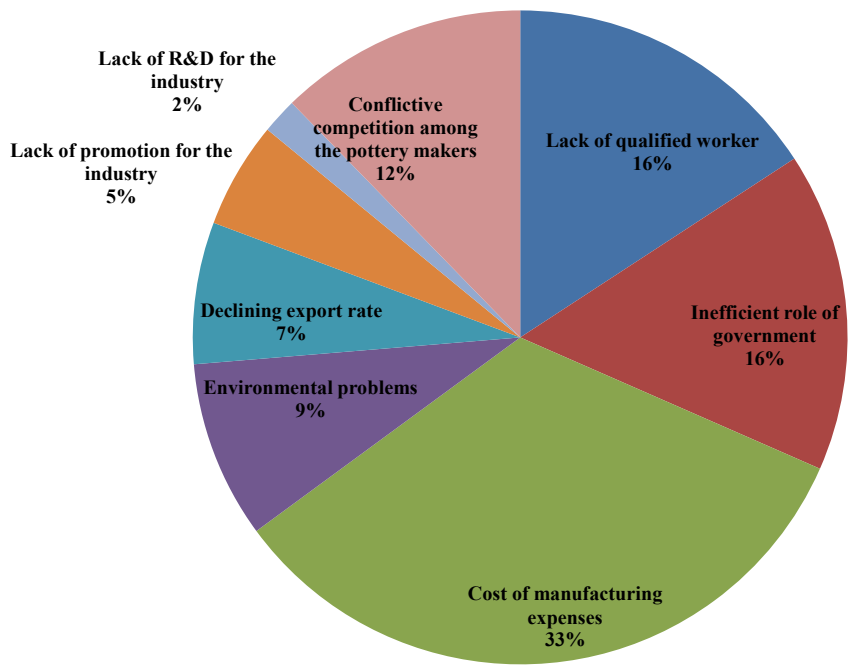

Figure 4: Obstacles of pottery making in Menemen.

The other two important problems are the lack of qualified workers available in the district since the attractiveness and appeal to work for the industry has declined, and the inefficient role of government, which directly related to the weak role of current NGOs. The other obstacles are conflictive competition among the ateliers, environmental problems, declining rate of export as well as 
the lack of promotion and research and development of this cultural industry in and around Menemen. While the inefficient usage of raw materials covers $60 \%$ of the reported environmental problems due to the recent changes at the local policies, environmental pollution and the cause of unhealthy smoke and ash are also considerable.

\section{Conclusion: sustaining the cultural industry in Menemen}

Along with the globally competitive environment, cities are now seeking investment for promoting cultural production as cultural industries, creating ideas and products. Thus, a strategic approach including place branding and place identity appear as a means to achieve such end. Such an approach should definitely employ design and planning interventions as indicators. The Kulp Workshop as a collaborative practice realized by the Izmir University of Economics, Turkey, Academy of Fine Arts in Warsaw, Poland and Adam Mickiewicz Institute, Poland has proven that working with collaboration is essential, because successful collaboration also helps for better and sustainable use of resources, brings different interpretations of unfamiliar issues in different contexts and a range of perspectives by considering the issues from different point of views. In this respect, collaborations from other geographies can add considerably to the processes of place brand and identity formation. Such workshop series can be extended with the universities and educational centres located in Izmir. The workshop series not only increases understanding of the local problem, but also helps to transfer and exchange the unique knowledge of pottery making to other places. That is crucial when it comes to the place branding and identity aspects. Sharing and brainstorming and other promotional activities before and after these workshops can generate developments in the area in terms of both physical and industrial organizational.

Sustainability is a complex issue and limiting design and application only in one scale do not completely achieve to well-planned cultural industry based development. Therefore several steps have been taken into account. Regarding the findings from the case study including the workshop, site survey and interviews, not only specific to Menemen but also for the similar localities based on such cultural production, a model has been generated (Figure 5).

In terms of the social aspects of sustainable development, the regulations should be introduced to link the society to the cultural industries by maintaining the potential of knowledge and know-how transfer occurred within the families. Regarding the starting age of pottery making and the presence of masters, it also seems crucial to encourage the younger generation to be trained by certain educational institutions. The major obstacles at the site survey indicate the lack of research centre for the industry, cost of manufacturing expenses, and environmental problems can be solved through attracting educational institutions into the district. Besides, there should also be a research and development agency established in cooperation with the government to make developments to reduce the cost in the manufacturing processes as well as to also help to 


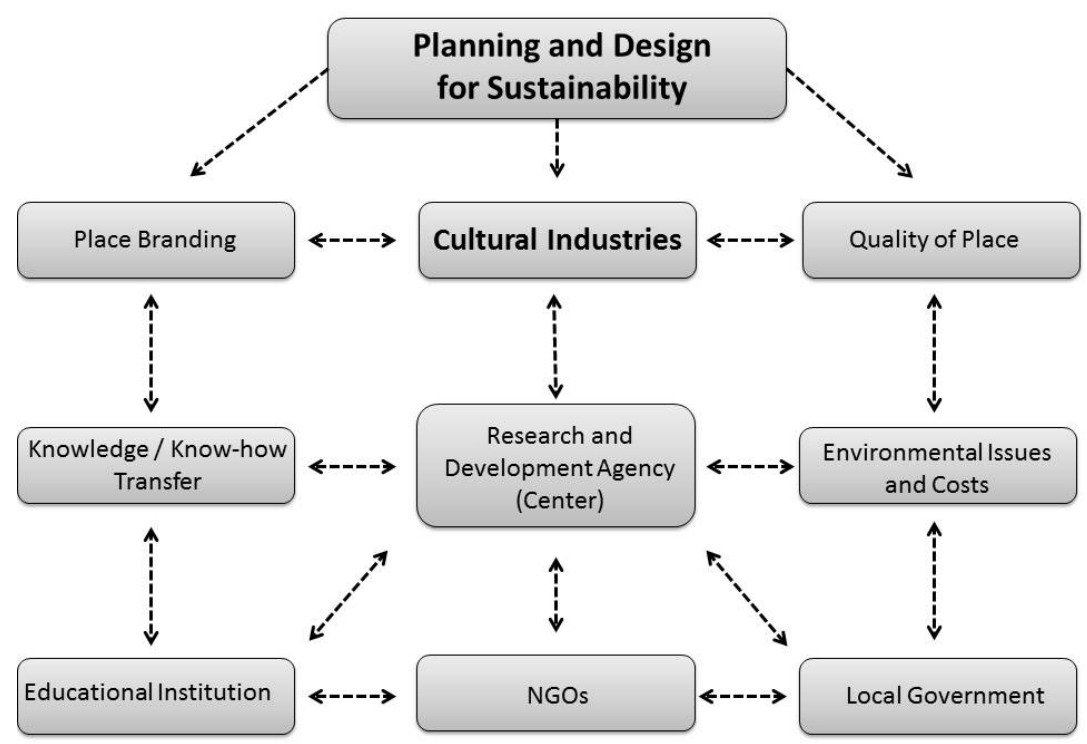

Figure 5: $\quad$ Proposed strategic model.

minimize the environmental problems. Research and development centres will also control and manage the particular aspects and skills of each pottery maker, distinguish originalities of each atelier, and help them to develop and promote their unique products accordingly. Managing the environmental problems will also increase the quality of place, which helps the branding. At the same time, such cooperation will enhance the role of local government and boost its reputation among the community. Such cooperation will boost the identity of place and incentives to the industry for its future development. The possible cooperation can also be supported via the NGOs, research centres, as well as educational institutions, complementary to the Menemen Pottery Making Association.

At the top of this sustainable model for cultural industries, there are planning and design decisions that must be made considering local situations and local needs.

Within the planning and urban design process of the cultural places, place branding should be aimed at image building and identity formation out of the cultural heritage and at boosting the attraction of the cultural production. It can involve a process of developing certain goals to achieve the long-term vision and objectives. Besides, place identity appears as an important indicator within the notion of place branding and place quality for cultural industries. No doubt identity is crucial in constructing and maintaining a sense of place. In the process of identity formation, there are a great awareness and investment found in the symbolic consumption and this should be indicated in the cultural places. For that reason, branding and quality dimensions of place should contain a 
comprehensive understanding of the characteristics of that particular location and cultural industry. In this case, environmental planners and designers need to be aware of the risks and potentials of the location and understand the effect of potential changes before deciding on possible solutions. Physical interventions through certain principles can also be found with the planning and design decisions. In order to have a great achievement on sustainable development there is an urgent need to integrate this concept into the planning and design processes, successfully. Collaboration among various interrelated institutions also creates community participation through the whole process, which is crucial for the long-term benefits for sustainability.

\section{Acknowledgement}

This article partially contains the initial outcomes of a scientific research project funded by Izmir University of Economics, Izmir, Turkey.

\section{References}

[1] Simmonds, R., Hack, G. (eds). Global City Regions: Their Emerging Forms. London and New York: Spon Press. 2000.

[2] Marcuse, P., \& Van Kempen, R. Conclusion: a changed spatial order. Globalizing Cities: A New Spatial Order? pp. 249-275. 2000.

[3] Brenner, N. Global Cities, Glocal States: Global City Formation as State Territorial Restructuring in Contemporary Europe. Review of International Political Economy, 5 (1), pp. 1-37. 1998.

[4] Soja, E. Postmodern geographies: The reassertion of space in critical social theory. London: Verso. 1989.

[5] O'Connor, J., The cultural production sector in Manchester: research and strategy. Manchester Institute for Popular Culture, Manchester Metropolitan University. 1999.

[6] Bianchini, F. and Parkinson, M., Cultural policy and urban regeneration; The West European Experience. Manchester University Press, Manchester. 1993.

[7] Garnham, N., Afterword: the cultural commodity and cultural policy. pp. 445-458 in Selwood, S. (eds), The UK Cultural Sector: Profile and Policy Issue. University of Westminster: Policy Studies Institute. 2001.

[8] O'Connor, J. and Wynne, D., From the Margins to the Centre: Cultural Production and Consumption in the Post-Industrial City, papers in Popular Cultural Studies, No. 7. 1993.

[9] Scott, A. J. Geography and Economy. Oxford University Press. 2006.

[10] Landry, C. and Bianchini, F., The creative city (Vol. 12). Demos. 1995.

[11] Hutton, T. A., The New Economy of the Inner City: Restructuring, Regeneration and Dislocation in the Twenty-first-century Metropolis. Abingdon, New York: Routledge. 2008.

[12] Kunzmann, K. R., Culture, creativity and spatial planning. Town planning review, 75(4), pp. 383-404. 2004. 
584 Sustainable Development and Planning VII

[13] Törnqvist G., Creativity and the renewal of regional life, in: A. Buttimer, (Ed.) Creativity and Context: A Seminar Report, pp. 91-112. Lund Studies in Geography. B. Human Geography, No. 50. Lund: Gleerup. 1983.

[14] Scott, A. J., The cultural economy of cities, International Journal of Urban and Regional Research, Vol. 21, No.2, pp. 323-339. 1997.

[15] Turkish Statistical Institute (ABPRS). Turkish Statistical Institute Address Based Population Registration System Website (Online): Accessed 20 Dec 2014, http://tuikapp.tuik.gov.tr/adnksdagitapp/adnks.zul?dil=2. 